\section{OP0060 SAFETY PROFILE OF ETANERCEPT IN LONG-TERM USE IN PATIENTS WITH JUVENILE IDIOPATHIC ARTHRITIS (JIA)}

Jens Klotsche ${ }^{1,2}$, Ariane Klein ${ }^{3}$, Martina Niewerth ${ }^{1}$, Gerd Ganser ${ }^{4}$, Peer Aries ${ }^{5}$, Marisa Walther ${ }^{6}$, Peter Haas ${ }^{7}$, Gernot Keyßer ${ }^{8}$, Gerd Horneff ${ }^{3}$, Kirsten Minden ${ }^{1,2}$. ${ }^{1}$ German Rheumatism Research Center, Berlin, Germany, ${ }^{2}$ Charité Universitätsmedizin Berlin, Berlin, Germany; ${ }^{3}$ Asklepios Kinderklinik St. Augustin GmbH, St. Augustin, Germany; ${ }^{4}$ St-Josef-Stift Sendenhorst, Sendenhorst, Germany, ${ }^{5}$ Internistisch-Rheumatologische Praxis, Hamburg, Germany; ${ }^{6}$ Das Endokrinologikum, Berlin, Germany; ${ }^{7}$ Zentrum für Kinder- und Jugendrheumatologie, Garmisch-Partenkirchen, Germany; ${ }^{8}$ Universitätsklinikum Halle, Rheumatologie, Halle, Germany

Background: Etanercept is the most frequently used biologic drug in patients with JIA. Children and adolescents with JIA are treated with etanercept often over long periods of time, sometimes even into adulthood. The knowledge about its long-term safety, especially with regard to the occurrence of new-onset immunemediated diseases and malignancies, is still limited.

Objectives: To investigate the exposure-adjusted rates of adverse events (AE) and serious $\mathrm{AE}$ (SAE) in patients with JIA with long-term use of etanercept.

Methods: Patients with JIA who were enrolled in the German biologic register BiKeR and were born before 30.05.2000 (at least 18 years of age at this date) were considered for this analysis. The follow-up register JuMBO ensures the long-term follow-up into adulthood. An AE or SAE was attributed to etanercept when the treatment was either ongoing or terminated in less than 3 month prior to the event. The incidence of malignancies was estimated in patients who were ever exposed to etanercept with at least one dose.

Results: Of 4546 patients who were currently enrolled in BiKeR a total of 2584 JIA patients were eligible for the JuMBO register (>18 years). Among those, 1765 $(68 \%)$ were ever exposed to etanercept and observed for a mean of $6.8 \pm 4.9$ years (including 1101 into adulthood). The majority of them had polyarthritis $(35 \%)$, followed by enthesitis-related arthritis (20\%) and extended oligoarthritis (17\%). The patients were exposed to etanercept for a total of 4.2 years (mean, 6,726 exposure years, EY); 518 patients were continuously treated with etanercept for at least 5 years $(4,534 \mathrm{EY})$. In total, 124 autoimmune events $(1.84 / 100 \mathrm{EY})$ and 7 other immune disorders $(0.10 / 100 \mathrm{EY})$ were reported in $102(5.8 \%)$ and $7(0.4 \%)$ patients with onset on average 10.2 years after JIA onset, and 6.8 years after start with etanercept, respectively. The number of selected immune-mediated events and the exposure-adjusted rates are given in the table. In addition, 11 malignancies (0.10 events/100 person-years) were reported in patients ever exposed to etanercept. Among those (mean age at onset 20.3 years), 4 malignancies were reported in childhood and 7 in young adulthood. Three patients were also exposed to other biologics before the incidence of malignancy. The malignancies occurred on average 12.1 years after JIA onset, 10.4 years after start with a first DMARD and 7.5 years after first exposure to etanercept.

Conclusion: This is the first long-term large safety study in prospectively followed JIA patients with focus on new-onset immune-mediated diseases and malignancies in etanercept. The study also highlights that it is important to prospectively collect data on adverse events under treatment with biologics in JIA, in particular with respect to the risk of malignancies in young adulthood.

Table 1. Adverse and serious adverse events under treatment with etanercept

\begin{tabular}{|c|c|c|c|c|}
\hline & All patients svert & reated with etanercept, n=1765 & Patients continu & $\begin{array}{l}\text { ouslytreated with etanercept for at } \\
\text { least } 5 \text { vears, } n=518\end{array}$ \\
\hline & Number of partients & $\begin{array}{c}\text { Number of reported events (rate } \\
1100 \mathrm{E})\end{array}$ & Number of patient. & $\begin{array}{l}\text { Number of reported everts (rate } \\
100 \mathrm{Er})\end{array}$ \\
\hline Serious atverse events & $218(7.3 \%)$ & $320(4.76)$ & $116(22.485)$ & $189(4.17)$ \\
\hline All infections & $285(16.1 \%)$ & $469(6.97)$ & $124(23.968)$ & $238(5.25)$ \\
\hline Medically important infections & $56(32 \% \%)$ & $69(1.03)$ & $31(6.08)$ & $43(0.95)$ \\
\hline Autoimmune disorder everts & $102(5.8 \%)$ & $124(1.84)$ & $49(0.5 \%)$ & $59(1.30)$ \\
\hline Uveits & $72(4.1 \%)$ & $87(1.29)$ & $37(7.1 \%)$ & $43(0.95)$ \\
\hline Inflammatory bowel dise seses & $22(1.2 \%)$ & $28\{0.42\}$ & $8(1.5 \%)$ & $11(0.24)$ \\
\hline Dempelinatrng dsorders & 3(0.28) & $3(0.06)$ & $2(0.48)$ & $2(004)$ \\
\hline Autoimmune hepartits & 1(0.1\%) & $1(0.01)$ & $10.2 \%)$ & $1(0.02)$ \\
\hline Autoimmune thyroiditis & 10.186) & 1 (a.01) & $1(0.280)$ & 1(0.02) \\
\hline Encephalitis sutcimmune & 1(0.1\%) & $1(0.01)$ & 0 & $0(0.00)$ \\
\hline Histiocytosis hsematophsgic & 1(0.1\%) & $1(0.01)$ & 0 & $0(0.00)$ \\
\hline ident timmune disorders & $7(0.4 \%)$ & $7(0.10)$ & 6(1.2.25) & $6(0.13)$ \\
\hline Vasculitides & $2(0.18)$ & $2(0.03)$ & $2(0.48)$ & $2(0.04)$ \\
\hline Psoriasis & $4(0.2 \%)$ & $4(0.06)$ & $3(0.65)$ & $3(0.07)$ \\
\hline Entheman nodosum & 10.1\%) & $1(0.01)$ & $10.2 \%)$ & $1(0.02)$ \\
\hline
\end{tabular}

Disclosure of Interests: Jens Klotsche: None declared, Ariane Klein: None declared, Martina Niewerth: None declared, Gerd Ganser: None declared, Peer Aries: None declared, Marisa Walther: None declared, Peter Haas Grant/research support from: Pfizer, Gernot Keyßer: None declared, Gerd Horneff: None declared, Kirsten Minden Consultant for: AbbVie

DOI: 10.1136/annrheumdis-2019-eular.5509

\section{OP0061 CONSUMER PERSPECTIVE ON PAEDIATRIC RHEUMATOLOGY CARE AND SERVICE DELIVERY: RESULTS FROM AN EARLY JUVENILE IDIOPATHIC ARTHRITIS (JIA) COHORT STUDY}

Michaela Heinrich ${ }^{1}$, Jens Klotsche ${ }^{2}$, Claudia Sengler ${ }^{2}$, Martina Niewerth², Frank Weller-Heinemann ${ }^{3}$, Peter Haas ${ }^{4}$, Gerd Horneff ${ }^{5}$, Toni Hospach ${ }^{6}$, Kirsten Moenkemoeller ${ }^{7}$, Angelika Thon ${ }^{8}$, Ivan Foeldvari ${ }^{9}$, Kirsten Minden ${ }^{1}$. ${ }^{1}$ Charité Universitätsmedizin Berlin, Berlin, Germany; ${ }^{2}$ German Rheumatism Research Centre, Berlin, Germany; ${ }^{3}$ ICON study group, Bremen, Germany; ${ }^{4}$ ICON study group, Garmisch-Partenkirchen, Germany, ${ }^{5}$ ICON study group, Sankt Augustin, Germany; ${ }^{6}$ ICON study group, Stuttgart, Germany; ${ }^{7}$ ICON study group, Köln, Germany; ${ }^{8}$ ICON study group, Hannover, Germany; ${ }^{9}$ ICON study group, Hamburg, Germany

Background: Timely access to specialized and multidisciplinary care is a core principle in the management of JIA patients and crucial to achieve the best possible outcome for children and adolescents with JIA.

Objectives: To assess satisfaction with access to specialized care and used health care services of families with children with JIA and to identify factors associated with unmet needs.

Methods: Parents of JIA patients enrolled in the early JIA cohort study ICON completed the Child Healthcare Questionnaire on Satisfaction, Utilisation and Needs (CHC-SUN) ${ }^{1}$ and the Family Burden Questionnaire (FaBel) 3 months after enrolment. The socioeconomic status, disease activity, patients' functional ability and quality of life were also assessed. Factors associated with unmet needs were identified by logistic regression analysis.

Results: Data were available from 835 families with children diagnosed with JIA 3 months (median, IQR 1-6) after symptom onset and cared for by paediatric rheumatologists (68\% females). At assessment (4.6 months after diagnosis, median), $67 \%$ of patients received non-steroidal anti-inflammatory drugs, $50 \%$ received conventional synthetic DMARDs and $8 \%$ biologic DMARDs. In addition, the following health care services were utilized: $84 \%$ physiotherapy, $23 \%$ occupational therapy, $21 \%$ supply with physical aids, $17 \%$ telephone counselling, $15 \%$ health education, $13 \%$ social worker services, and $11 \%$ psychological counselling. Unmet needs were most frequently reported for health education (19\%), rehabilitation services $(11 \%)$, psychological counselling $(11 \%)$, self-help groups $(10 \%)$, and lowest for physiotherapy (2\%). Unmet needs varied depending on the type of service and JIA category (Table). They were more frequently observed in families with higher burden as indicated by FaBel, but were not associated with migration background and socioeconomic status. Most parents were generally satisfied with their child's health care (satisfied $30 \%$, very satisfied $42 \%$, extremely satisfied $23 \%)$. Satisfaction was highest with the behaviour of doctors and lowest with school-related services (e.g. 36\% not or partly satisfied with teachers' knowledge about the child's illness) and diagnosis/information (e.g. $29 \%$ not or partly satisfied with the time required for the diagnosis).

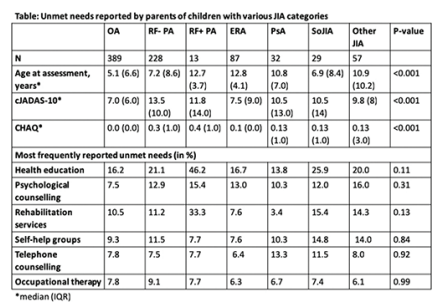

Conclusion: There are, although infrequently, unmet needs and dissatisfaction with health services among families with children who have JIA and receive specialized care. Whether these deficits are relevant for long-term JIA outcomes will be further investigated in the ICON study.

\section{REFERENCE:}

[1] Schmidt S, Thyen U, Chaplin J, Mueller-Godeffroy E; European DISAB KIDS Group. Cross-cultural development of a child health care questionnaire on satisfaction, utilization, and needs. Ambul Pediatr. 2007:7:374-82.

Acknowledgement: Funding by Federal Ministry of Research: 01 ER 1504A Disclosure of Interests: Michaela Heinrich: None declared, Jens Klotsche: None declared, Claudia Sengler: None declared, Martina Niewerth: None declared, Frank Weller-Heinemann: None declared, Peter Haas Grant/research support from: Pfizer, Gerd Horneff: None declared, Toni Hospach Speakers bureau: Chugai, Roche, Novartis, Kirsten Moenkemoeller: None declared, Angelika Thon: None declared, Ivan Foeldvari Consultant for: Chugai, Novartis, Kirsten Minden Consultant for: AbbVie DOI: 10.1136/annrheumdis-2019-eular.5028 